\title{
UMA ANÁLISE DO PERFIL DA MULHER NO MERCADO DE TRABALHO FORMAL BRASILEIRO NO PERÍODO 2002-2014
}

\author{
Gabriella do Nascimento Pinheiro ${ }^{1}$, Fabiola de Sampaio Rodrigues Grazinoli Garrido ${ }^{2}$ \\ ${ }^{1}$ Economista pela Universidade Federal Rural do Rio de Janeiro e Mestranda em Economia pela Universidade Federal \\ Fluminense - PPGE. E-mail: gabinp@outlook.com. Agência de fomento: Programa de Educação Tutorial (PET). \\ ${ }^{2}$ Professora Associada, DCMA/PPGPDS - UFRRJ, Programa de Educação Tutorial Conexões de Saberes por uma \\ Formação Integradora e Cidadã no Campus de Três Rios da UFRRJ. E-mail: fabiola_srg@yahoo.com.br.
}

\section{RESUMO}

As mulheres e o mercado de trabalho compõem dois assuntos que têm sido discutidos em conjunto com forte ênfase na sociedade. Elas a cada dia vêm conquistando seus objetivos graças às suas lutas em busca de seus direitos por espaços nos avanços políticos, econômicos, sociais e culturais. O objetivo deste trabalho foi de evidenciar a evolução da trabalhadora feminina nos anos atuais no mercado de trabalho formal brasileiro, bem como caracterizar o perfil da mesma. Assim, a fim de complementar os levantamentos bibliográficos, foram feitos cruzamentos de dados obtidos através da Relação Anual de Informações Sociais (RAIS) solicitado pelo Ministério do Trabalho e Emprego (MTE). Os resultados foram promissores de modo que apresentaram uma forte tendência ascendente da participação feminina encontradas nos vínculos empregatícios em sua maioria com a faixa etária entre 30-39 anos, no setor de comércio, com bom nível escolar e com remuneração entre 1,00 a 1,50 salário mínimo.

Palavras-chave: mulher, trabalho, gênero, economia, salário

\section{AN ANALYSIS OF THE PROFILE OF WOMAN IN BRAZILIAN FORMAL LABOUR MARKET IN THE PERIOD 2002- 2014}

\begin{abstract}
Women and the labour market are two widely discussed issues in society. Each day, they have reached their objectives due to their constant search of room in political, economical, social and cultural advances. The objective of this work was to highlight female worker evolution in Brazilian formal working market, as well as to point out their profile in the recent years. In adition to the bibliographic researches, data analysis was done through Annual Social Information Database, commonly known as RAIS, requested to employees by the Brazilian Ministry of Labour and Employment - MTE. Results were quite promising, because there was increasing female participation found among workers. The great concentration was between 30 to 39 years-old women, in trade sector, with considerable scholar level and salary reaching 1 to 1,5 minimum wage.
\end{abstract}

Keywords: woman, work, gender, economy, salary

\section{INTRODUÇÃO}

No mercado de trabalho brasileiro, os termos econômicos, políticos e históricos devem ser considerados como determinantes de sua formação, manutenção e também de suas características, fazendo com que o mesmo seja tratado em sentido específico e sem comparações por ter seus próprios atributos (BARBOSA, 2003). Um destes atributos é refletido no âmbito da trajetória e permanência da força de trabalho feminino nos vínculos empregatícios, como por exemplo, a existência de barreiras culturais e discriminatórias, a desigualdade no nível salarial e postos de trabalhos inferiores aos do gênero masculino. Por muito tempo, restringiu-se a elas o perfil de cuidadora da casa, do esposo, dos filhos e de realização de alguns afazeres sociais não remunerados. Até hoje as mulheres são grande maioria dos chefes de família e, em muitos casos, detém jornadas de 
trabalho que não contabilizam os cuidados familiares ou fazem opção por trabalhos que permitam a manutenção dos modelos tradicionais de família.

Análises feitas sobre este tema atualmente comprovam que a participação feminina vem ganhando espaço no sentido ascendente a partir do período pós-guerra. Tal conquista é resultado de inúmeras lutas das mulheres por direitos, onde pode-se destacar o movimento feminista, o qual garantiu não só oportunidades dentro do ambiente laboral, como também o direito ao voto, o acesso das mulheres às universidades e a adoção de práticas contraceptivas, entre outras conquistas. A partir de tal contexto, o objetivo deste estudo foi concentrado em determinar o perfil da mulher no mercado de trabalho formal brasileiro atualmente, de modo a analisar a evolução da participação da trabalhadora brasileira no período.

\section{METODOLOGIA}

Foi feito levantamento de contextos históricos e atuais, além de cruzamentos de dados que foram obtidos através do relatório de informações socioeconômicas solicitado pelo Ministério do Trabalho e Emprego (MTE) às pessoas jurídicas e outros empregadores denominado de Relação Anual de Informações Sociais $^{1}$ (RAIS), que disponibiliza dados dos vínculos empregatícios formais da administração pública e privada e de empregadores cadastrados no INSS no período 2002-2014. Vínculos empregatícios é entendido como as relações de emprego em que o trabalho é remunerado.

O processo metodológico utilizado neste trabalho consistiu em tabular os principais dados utilizados a partir de séries históricas sobre as variáveis relativas ao perfil dos vínculos empregatícios do gênero feminino no período proposto, como: o número de trabalhadoras, para evidenciar a evolução ao longo do tempo; faixa etária; setores de trabalho - os quais foram divididos nos cinco grandes setores da economia segundo o IBGE: indústria, comércio, serviços, construção civil e agropecuária -; e grau de escolaridade e taxa de remuneração média tendo como referência o salário mínimo.

\section{RESULTADOS}

A figura 1 aponta uma realidade fundamentada: o crescimento do emprego formalizado em detrimento daquele sem carteira. Segundo Leone e Baltar (2008), a participação da mulher aumentou, apesar da persistência das grandes diferenças de renda por sexo. Isso demonstra empiricamente a evolução das mulheres no mercado de trabalho dado que durante o período, teve uma evolução consideravelmente ascendente.

\footnotetext{
1 De acordo com o Comitê de Estatísticas Sociais do Instituto Brasileiro de Geografia e Estatística, os dados da RAIS têm como objetivo a elaboração de diagnósticos sobre o mercado de trabalho servindo como base à elaboração de pesquisas estatísticas como esta.
} 


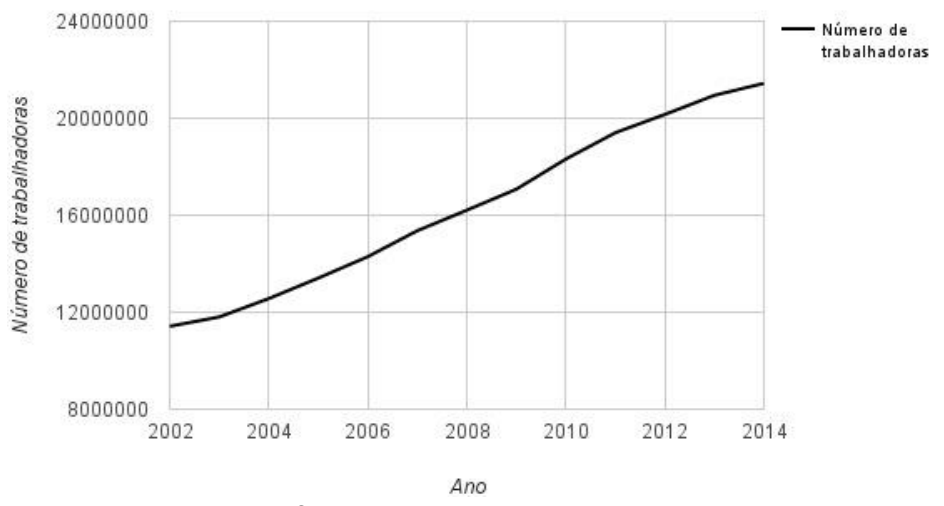

Figura 1. Comportamento da participação feminina no mercado de trabalho - Brasil, 2002 a 2014 Fonte: RAIS/MTE.

Outro dado relevante para compor o perfil proposto é a faixa etária. O maior grupo etário participativo no mercado de trabalho corresponde à faixa de 30-39 anos. Pode-se observar também que mulheres fora da idade fértil, com 50-64 anos, tiveram uma participação significativa nos incrementos de mulheres no mercado de trabalho. A figura 2 retrata esse incremento, contra uma queda proporcional na participação de mulheres mais jovens, nas faixas de $18-24$ e $25-29$ anos. Nesse período, essas jovens e mães contam com os programas de transferência de renda do governo e a maioria pode se dedicar aos cuidados familiares, tendo em vista incentivos governamentais à manutenção de crianças nas escolas até os 16 anos.

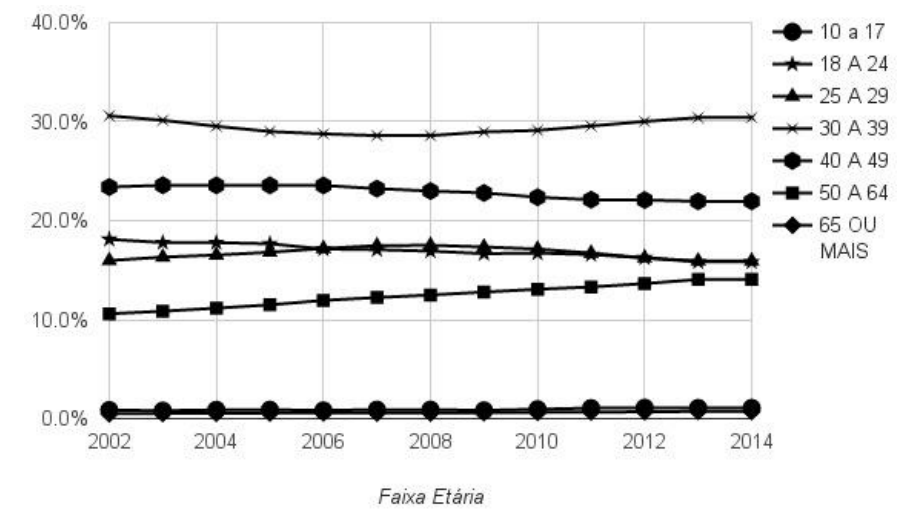

Figura 2. Comportamento do número de mulheres no mercado de trabalho formal de acordo com a faixa etária - Brasil, 2002 a 2013. Fonte: RAIS/MTE.

A figura 3 demonstra a alocação das trabalhadoras nos cinco grandes setores da economia segundo o Instituto Brasileiro de Geografia e Estatística (IBGE). Observa-se uma grande massa das mulheres empregadas no setor de serviços, correspondendo a mais da metade, sendo seguido pelos setores de comércio, indústria, agropecuária e construção civil. Tal fato demonstra uma forte segregação de gênero entre os setores da economia. 


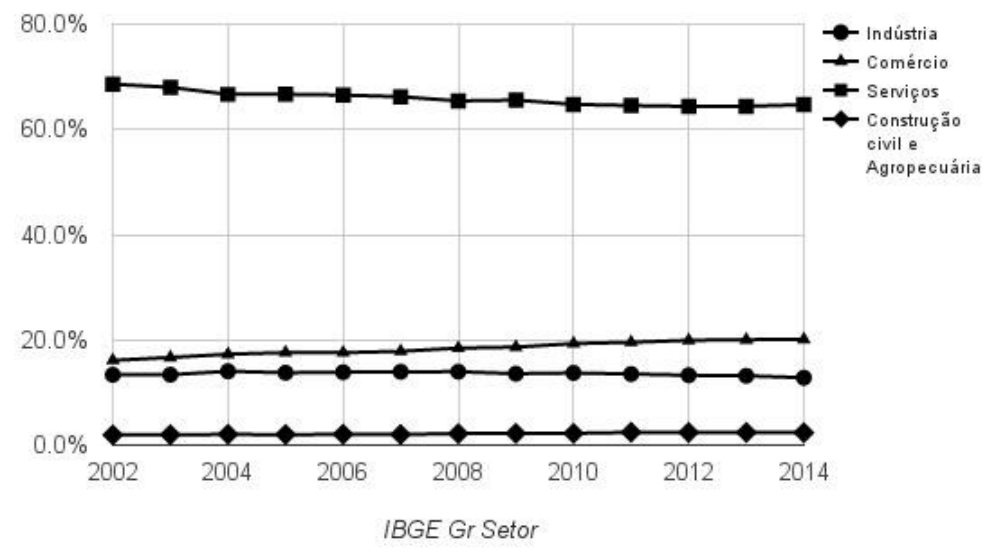

Figura 3. Comportamento da participação das mulheres nos grandes setores do IBGE no trabalho formal Brasil, 2002 a 2014. Fonte: RAIS/MTE.

Outro parâmetro a ser discutido é como a mulher vem se preparando para ingressar no mercado de trabalho e tal preparação é refletida no seu nível de escolaridade. É fato que os valores relativos de mulheres com mais anos de estudos empregadas sejam maiores. Essa população com mais estudos corrobora a elevação do nível educacional que em 2009 ultrapassava a média nacional de 7,1 anos (Ensino Fundamental incompleto). Atualmente, $75 \%$ dos jovens já estudaram mais do que seus pais (Gandra, 2015). Com ensino médio completo, a colocação no mercado de trabalho é mais provável. Apesar disso, a exigência de ensino médio completo, que foi alavancada na década de 1990, muitas vezes é um protocolo, não a busca por habilidades cuja escolaridade possa proporcionar. Um exemplo é a exigência de ensino médio completo para desempenhar atividades no comércio, independentemente da função.

De acordo com os dados da RAIS, O analfabetismo entre mulheres que era de 129.687 no ano de 2002 teve uma queda drástica para 21.949 analisada no último período do nosso ano, $2014^{2}$. Ainda em conformidade com os dados aqui utilizados, elas estão em sua maioria no ensino médio completo - em números, isso corresponde a 10.070 .950 no ano de 2014. Um outro fator importante é o forte crescimento da participação feminina no nível superior e a constatação de que as mulheres se dedicam aos estudos. No ano de 2002, apenas um pouco mais de 2 milhões de mulheres tinham curso superior completo. Com o decorrer do período, este número subiu para um pouco mais de 5,5 milhões de mulheres no ano de 2014. Neste último ano ainda, foi também constatado que um pouco menos de 150 mil mulheres tinham mestrado e um pouco mais de $40 \mathrm{mil}$, doutorado.

Essa participação feminina com mais estudos e concentrada no setor de serviços trouxe consigo a renda de 1,01 a 1,50 salários mínimos ao mês, como pode ser observado na figura 4. Esse quadro é agravado quando se comparam os recebimentos de mulheres aos de homens ocupando os mesmos cargos, o que está em torno de $78 \%$ do que homens recebem.

\footnotetext{
${ }^{2}$ Esse avanço ainda pode ser maior, com investimentos pesados em educação e respeito à diversidade regional, com realidades praticamente inacessíveis à escola e aos professores, como aldeias indígenas, assentamentos, populações quilombolas, locais em que exploram o trabalho infantil, entre outras.
} 


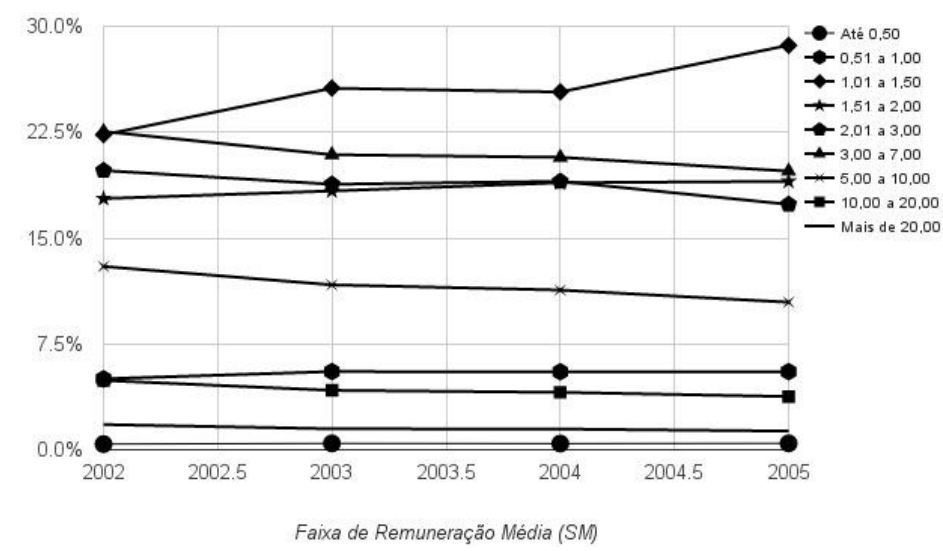

Figura 4. Comportamento do da taxa de remuneração média das mulheres no mercado de trabalho formal - Brasil, 2006 a 2014. Fonte: RAIS/MTE.

A figura acima reforça a estagnação das mulheres no setor de serviços dado que as menores faixas salariais estão compatíveis com o setor em que elas estão alocadas.

\section{DISCUSSÃO}

A percepção em relação ao avanço da força feminina no mercado de trabalho vem sendo acompanhado com notoriedade (Scorzafave e Menezes-Filho, 2001; Goldani, 2002; Bruschini, 2007). É importante ressaltar que as conquistas em função da evolução da presença feminina no mercado laboral foram constituídas por vários pontos - o movimento feminista, antes denominado de movimento feminino, 0 acesso das mulheres às universidades, a adoção das práticas contraceptivas (VAZ e LAIMER, s. d.).

É provável que a retirada de trabalhadoras da informalidade tenha contribuído para o aumento significativo desta formalização da força de trabalho feminina. A regulamentação da profissão de empregada doméstica, com a Lei no 11.324/2006, foi uma aliada importante para consolidar os aumentos da participação feminina no mercado de trabalho formal (Guimarães et. al, 2013).

Além disso, a demanda de qualificação iniciada na década de 1990, associada à política de interiorização das universidades brasileiras (Reuni - Reestruturação e Expansão das Universidades Federais), ao PRONATEC (Programa Nacional de Acesso à Escola Técnica), e incentivos à elevação do nível educacional das pessoas podem ter sido determinantes para serem percebidos no aumento da força de trabalho feminina no mercado formal.

Outro fator de forte contribuição para a evolução da participação feminina no mercado de trabalho foi a queda da taxa de fecundidade. Dessa forma, ao se acompanhar a taxa de fecundidade, de acordo com o IBGE, pode-se observar a redução do número de filhos de 2,6 para 1,74 por família. Trabalhar e manter os filhos e outros familiares implica deter uma rede de cuidadores pelos quais a trabalhadora ainda não pode pagar.

Os dados demonstraram que elas se encontram nos vínculos empregatícios em sua maioria na faixa etária de 30-39 anos, nos setores de comércio - refletindo uma segregação de setores entre os gêneros -, possuindo melhora significativa nos níveis educacionais, porém, infelizmente, com remunerações inferiores ao que merecem por conta de barreiras desiguais entre gêneros.

\section{CONCLUSÃO}

Aqui estão as mulheres. Têm aumentado os anos de estudos, cuidam das famílias, não equiparam seus proventos aos recebimentos de homens nos mesmos cargos e estão estagnadas no setor de comércio. Neste sentido, acredita-se que o trabalho de acompanhamento da paridade de gênero nos anos iniciais da vida escolar possa resultar em uma sociedade com mais mulheres presentes na vida política do país. Isso pode gerar a consolidação do trabalho feminino, que nasceu mundialmente no período sem homens economicamente ativos e pode atingir a paridade quando as pequenas brasileiras ingressarem mais frequentemente em universidades.

Há que se privilegiar a instituição de políticas públicas mais sólidas ou até mesmo redesenhos de políticas atuais com o objetivo de dar maior atenção aos papéis de gênero. A implementação de políticas de gênero voltadas para as atividades geradoras de renda, 
ocasionando numa mudança de rumo, onde o foco passa a ser realçado pelas atividades produtivas das mulheres (NOVELLINO, 2004; MARIANO e CARLOTO, 2011).

\section{REFERÊNCIAS}

BARBOSA, A. A Formação do Mercado de Trabalho no Brasil: da escravidão ao assalariamento. 2003. Tese de Doutorado (Economia Social e do Trabalho). Campinas: Unicamp.

BRASIL. Lei $n^{\circ} \mathbf{1 3 . 2 7 2}$ de 15 de abril de 2016 . Disponível em: <http://www.planalto.gov.br/CCIVIL_03/Ato201 5-2018/2016/Lei/L13272.htm>. Acesso em: 10 ago. 2016.

BRUSCHINI, M. C. A. Trabalho e Gênero no Brasil nos Últimos Dez Anos. Cadernos de Pesquisa, v. 37, n. 132, p. 537-572, set./dez. 2007. https://doi.org/10.1590/s0100-

\section{3}

COMITÊ DE ESTATÍSTICAS SOCIAS (CES). Disponível em: <http://ces.ibge.gov.br/base-dedados/metadados/mte/relacao-anual-deinformacoes-sociais-rais.html>. Acesso em: 27 ago. 2016.

GANDRA, A. Escolaridade do brasileiro sobe 8 pontos percentuais em 10 anos, mostra pesquisa. EBC Agência Brasil. Disponível em: <http://agenciabrasil.ebc.com.br/educacao/notic ia/2015-04/data-popular-escolaridade-dobrasileiro-sobe-8-pontos-percentuais-em-dez> Acesso em: 10 ago. 2016.

GOLDANI, A. M. Família, gênero e políticas: famílias brasileiras nos anos 90 e seus desafios como fator de proteção. Revista Brasileira de Estudos de População, v.19, n.1, jan./jun. 2002, p. 29-48.

GUIMARÃES, F. R.; AZEVEDO, D. A. G. de, CAVALCANTE; J. P. S.; FRANÇA-NETO, J. L. Retratos da Desigualdade: Identidade Social e Condições de Trabalho das Empregadas Domésticas no Brasil (2004 - 2013). Revista Dat@venia, vol. 08, no 11, p. 09-19.

INSTITUTO BRASILEIRO DE GEOGRAFIA E ESTATÍSTICA (IBGE). Disponível em: <http://www.ibge.gov.br>. Acesso em: 13 abr. 2016.

LEONE, E. T.; BALTAR, P. A mulher na Recuperação Recente do Mercado de Trabalho Brasileiro. Revista Bras. Est. Pop., São Paulo, v. 25, n. 2, p. 233-249, jul./dez. 2008.

MARIANO, Silvana Aparecida; CARLOTO, Cássia Maria. Gênero e Combate à Pobreza no Bolsa
Família. In: BONETTI, Alinne de Lima; ABREU, Maria Aparecida A. Faces da Desigualdade de Gênero e Raça no Brasil. Brasília: Ipea, 2011, p. 61-78.

NOVELLINO, Maria Salet Ferreira. Os Estudos Sobre a Feminização da Pobreza e Políticas Públicas Para Mulheres. XIV Encontro Nacional de Estudos Populacionais, ABEP. Caxambú/MG Brasil. Setembro de 2004.

SCORZAFAVE, L. G. e MENEZES-FILHO, N. A. Participação feminina no mercado de trabalho brasileiro: evolução e determinantes. Pesq. Plan. Econ., v. 31, n. 3, p. 441-447, dez. 2001.

VAZ, Caroline F. M. e LAIMER, Rosane T. A inserção da mulher no mercado de trabalho e o surgimento da profissão secretária. Disponível em:

<http://www.upf.br/seer/index.php/ser/article/v iew/1783>. Acesso em: 10 ago. 2016.

Recebido para publicação em 19/08/2016

Revisado em 26/08/2016

Aceito em 02/09/2016 